\title{
Turismo como vetor de desenvolvimento local: análise da estrutura turística no Município de São José do Barreiro - SP
}

\author{
Monica Franchi Carniello \\ Universidade de Taubaté \\ Cláudia Liciely Barbosa e Silva \\ Uniesp Guaratinguetá
}

\section{Resumo}

O turismo se apresenta como um vetor de desenvolvimento local e regional, quando a estrutura turística considera o potencial endógeno do município, converge com os interesses dos atores locais e gera emprego e renda revertidos para a população local. $O$ objetivo deste artigo foi verificar como o município São José do Barreiro - SP organiza e estrutura sua atividade turística com vistas ao desenvolvimento local. O município apresenta o status de estância turística, pertence à região Metropolitana do Vale do Paraíba Paulista e Litoral Norte e teve a dimensão econômica classificada como de baixo desenvolvimento no Índice Firjan de Desenvolvimento Municipal 2013. A pesquisa, de caráter descritivo e abordagem quali-quantitativa, triangulou os métodos de observação dos atrativos turísticos; de entrevista com o gestor público municipal; e de aplicação de questionário à população. Foi identificado que o município possui potencial turístico, mas necessita de gestão pública eficaz na área do turismo, como também, de investimento em infraestrutura, planejamento turístico e divulgação dos atrativos existentes.

Palavras-chave: Desenvolvimento Local. Estrutura turística. Turismo.

Tourism as vector of local development: analysis of the tourist structure in the Municipality of São José do Barreiro - SP

\footnotetext{
Abstract

Tourism presents itself as a vector of local and regional development, when the tourism structure considers the endogenous potential of the municipality, converges with the interests of local actors and generates employment and income reverted to the local population. The objective of this article was to verify how the São José do Barreiro - SP municipality organizes and structures its tourist activity for local development. The municipality has the status of a tourist resort, belongs to the Metropolitan region of the Paraíba Paulista Valley and North Coast and had the economic dimension classified as low
} 
development in the Firjan Index of Municipal Development 2013. The research, with descriptive character and qualitative-quantitative approach, triangulated the methods of observation of the tourist attractions; interview with the municipal public manager; and questionnaire application to the population. It was identified that the municipality has tourist potential, but it needs effective public management in the area of tourism, as well as investment in infrastructure, tourism planning and dissemination of the existing attractions. Keywords: Local Development. Tourist structure. Tourism.

\section{Turismo como vector de desarrollo local: análisis de la estructura turística en el municipio de São José do Barreiro - SP}

\section{Resumen}

El turismo se presenta como un vector de desarrollo local y regional, cuando la estructura turística considera el potencial endógeno del municipio, converge con los intereses de los actores locales y genera empleo y renta invertidos para la población local. El objetivo de este artículo ha sido verificar cómo el municipio São José do Barreiro - SP organiza y estructura su actividad turística con vistas al desarrollo local. El municipio posee el estatus de estancia turística, pertenece a la región Metropolitana del Valle del Paraíba Paulista y Litoral Norte y tuvo la dimensión económica clasificada como de bajo desarrollo en el Índice Firjan de Desarrollo Municipal 2013. La investigación, de carácter descriptivo y abordaje cuali-cuantitativa, trianguló los métodos de observación de los atractivos turísticos; de entrevista con el gestor público municipal; y de aplicación de cuestionario a la población. Se identificó que el municipio posee potencial turístico, pero necesita una gestión pública eficaz en el área del turismo, como también, inversión en infraestructura, planificación turística y divulgación de los atractivos existentes.

Palabras clave: Desarrollo Local. Estructura turística. Turismo.

\section{Introdução}

O turismo é comumente apontado como uma solução para economias fragilizadas na produção industrial ou agrícola, como uma alternativa econômica para o desenvolvimento. Weidfeld (2018) enfatiza que o turismo é visto como uma alternativa ao declínio das indústrias tradicionais e a agricultura em geral, particularmente em regiões periféricas ditas atrasadas. Nestes casos, políticas territoriais podem promover estratégias de diversificação e, com isso, fomentar a atividade turística. $\mathrm{O}$ autor afirma que há localidades que dependem do turismo para sua diversificação e revitalização.

Este artigo parte do pressuposto que esta relação turismo-desenvolvimento é possível, mas não direta, pois depende de uma série de fatores, dentre os quais: a existência de um patrimônio material ou imaterial que possa ser gerido de maneira a gerar atratividade turística; a hospitalidade e predisposição dos atores locais de se envolverem e conviverem com a atividade turística; o planejamento e gestão do turismo, voltados para o desenvolvimento do município; a geração de emprego de qualidade e renda, de maneira a melhorar a qualidade de vida dos munícipes.

A estruturação da atividade turística, portanto, é fundamental para o alcance de um turismo para o desenvolvimento local, uma vez que, segundo Gogonea et al. (2017), embora o turismo tenha um efeito multiplicador no desenvolvimento de 
uma região, ele cria pressão sobre o meio ambiente como qualquer outra atividade econômica com potencial de capitalização.

Körössy (2008, p.56) destaca que "durante muito tempo, a ênfase sobre a atividade direcionou-se, quase que exclusivamente, aos aspectos econômicos e aos contributos que o turismo poderia desempenhar no Produto Interno Bruto (PIB)". Esta visão converge com a visão superada de desenvolvimento como sinonímia de crescimento e se afasta dos conceitos contemporâneos de desenvolvimento (FURTADO; 1964; SEN, 2000) que, guardadas as particularidades das vertentes teóricas, consideram, em última instância, a qualidade de vida e o bem-estar social como finalidade última dos processos de desenvolvimento.

O aproveitamento do potencial endógeno de um município pode ser uma maneira de se gerar uma distinção do território e, consequentemente, tornar-se um ativo das estratégias locais de desenvolvimento (FLORES, 2006). Para isso, a coordenação da atividade turística pela gestão pública municipal de maneira que os recursos materiais e imateriais sejam revertidos para o município é fundamental, evitando modelos de turismo predatório que chegam a prejudicar a qualidade de vida da população.

O município de São José do Barreiro, situado no chamado Vale Histórico Paulista, território cultural pertencente à Região Metropolitana do Vale do Paraíba e Litoral Norte, foi caracterizado por Monteiro Lobato, em 1919, no livro Cidades Mortas. A obra retratou decadência das cidades da cafeicultura na região, fato que ficou conhecido como "marcha do café" para o Oeste Paulista. É um local rico em belezas naturais e arquitetura típica da monocultura cafeeira decadente. "O legado arquitetônico resultante das atividades vinculadas à produção cafeeira encontra-se disseminado entre os municípios que compõe a microrregião [...]" (SANTOS, HANAOKA, CARNIELLO, 2015, p. 09).

Esses cenários históricos compõem a cultura regional e atraem interessados pela ruralidade e por um ambiente com mais qualidade de vida, envolvendo a natureza. Segundo Gutlich (2016, p.396)

vislumbrando um desdobramento de potencialidades a partir de iniciativas de turismo sustentável onde a microrregião e, em específico o município focado, tem despertado o interesse para uma série de iniciativas de boa repercussão associadas ao meio ambiente, às práticas de esportes que promovem o contato com a natureza (GUTLICH, 2016, p. 396).

Os visitantes do Vale Histórico Paulista apreciam o ambiente caipira e contemplam um Turismo Slow (lento) que "representa uma tentativa de conscientização e estímulo às pessoas, mostrando que existe outro caminho, uma alternativa para viver com mais qualidade" (NAIGEBORIN, 2011, p. 32). Nesse sentido, como o turismo vem se constituindo em uma área econômica favorável para os municípios com dificuldade de inserção em segmentos econômicos mais tradicionais, este artigo teve como objetivo verificar como o município São José do Barreiro - SP organiza e estrutura sua atividade turística com vistas ao desenvolvimento local. 
São José do Barreiro, denominado como estância turística, teve em 2013, o Índice de Desenvolvimento Humano Municipal - IDHM, de acordo com o Atlas de Desenvolvimento Humano no Brasil (2013), na posição $2.332^{\circ}$, considerado baixo, se comparado às demais estâncias turísticas do estado de São Paulo. Também no mesmo ano, segundo o Instituto Firjan (BRASIL, 2013), o município teve um Índice de Desenvolvimento Municipal - IFDM de 0,3718, referente ao emprego e renda, considerado de baixo desenvolvimento.

Ressalta-se que os baixos indicadores nem sempre se refletem diretamente na percepção negativa dos munícipes, no entanto, os indicadores devem ser considerados como um dos parâmetros para a avaliação da condição do território, e para a fundamentação do planejamento territorial.

Nesse sentido, o presente artigo discutirá a estrutura turística de São José do Barreiro, por meio da pesquisa com a gestão municipal e com a comunidade local e análise local do pesquisador que permitirá, em uma perspectiva indutiva, refletir sobre a relação turismo e desenvolvimento.

\section{Turismo e desenvolvimento local}

Para se estabelecer a relação entre turismo e desenvolvimento, primeiramente faz-se necessário definir desenvolvimento. Segundo Dallabrida (2011, p.4),

o desenvolvimento (local, regional, territorial) pode ser entendido como um processo de mudança estrutural empreendido por uma sociedade organizada territorialmente, sustentado na potencialização dos recursos e ativos (genéricos e específicos, materiais e imateriais) existentes no local, com vistas à dinamização socioeconômica e à melhoria da qualidade de vida de sua população.

Sachs (2003) acrescenta a dimensão temporal ao debate do desenvolvimento, formulando a ideia de desenvolvimento sustentável.

\footnotetext{
O desenvolvimento, se baseia, antes de mais nada, na capacidade de um povo em pensar a seu próprio respeito, dotar a si mesmo de um projeto, o que, evidentemente, remete à cultura e à ética com suas vertentes de solidariedade sincrônica com a geração presente e solidariedade diacrônica com as gerações futuras (SACHS, 2003, p.17).
}

O conceito de turismo sustentável é uma extensão da ideia de desenvolvimento sustentável aplicada ao turismo. O World Tourism Organization (WTO) considera o turismo sustentável como o caminho que atende às necessidades das partes interessadas, como turistas, o turismo, o meio ambiente e as comunidades locais, levando em conta os impactos econômicos, sociais e ambientais atuais e futuros (LIU et al., 2018). Ainda segundo os autores, para promover o conceito de desenvolvimento sustentável do turismo, é necessário analisar de maneira eficaz as práticas e iniciativas existentes de turismo sustentável, de modo a promover o desenvolvimento coordenado do turismo em todas as direções.

Em sua gênese, a evolução do turismo está diretamente ligada ao desenvolvimento do capitalismo, que possibilitou a criação de meios de transporte 
mais rápidos, e meios de hospedagens mais confortáveis para atender diversos públicos. As práticas fordistas proporcionaram, aos trabalhadores, descanso remunerado e férias, podendo, estes, usufruir de momentos de lazer. O turismo "já fora caracterizado como um fenômeno intrinsecamente moderno, considerando que os fatores que desencadearam o seu surgimento são oriundos da era moderna" (PIRES, 2009, p. 68). A discussão sobre turismo sustentável é atual e acompanha o debate do desenvolvimento em geral, ao buscar formas de estruturação do turismo que conciliem a atividade econômica com o desenvolvimento local e/ou regional.

A articulação dos atores locais com a gestão pública municipal é fundamental para evitar o turismo predatório, dominado exclusivamente por empresas de capital externo, gerando para os locais apenas emprego de baixa remuneração, custos de infraestrutura e impactos ambientais e culturais. "O desenvolvimento do turismo não é um processo econômico isolado, mas parte integral de uma transformação cultural, política, socioeconômica e estrutural maior" (ATELJEVIC; PAGE; ALMEIDA, 2001, p. 07). Liu et al (2018) alertam que regiões especializadas em turismo podem ser caracterizadas por oportunidades de desenvolvimento regional com base em recursos naturais e culturais, mas que podem não ser geridos de forma sustentável , o que pode resultar em um círculo vicioso no qual os serviços regionais atraem visitantes e não atendem de forma satisfatória a população local. Cidades com visibilidade turística global, como Veneza e Barcelona, têm vivenciado tal situação, conforme noticiado na imprensa (BARATA, 2017; G1, 2017).

Para Oliveira (2005), o não planejamento do turismo / a falta de planejamento do turismo provoca o crescimento desordenado, devido ao excesso de oferta de acomodações, ao aumento dos preços de produtos/serviços locais, bem como à degradação dos patrimônios naturais, e a criação de uma mentalidade mais oportunista que empresarial. Sendo assim, os municípios que não dispõem de planejamento turístico "enfrentam o paradoxo de conservarem belas paisagens e verem esse mesmo recurso dilapidado pela atividade turística. A cenarização passa a ser componente de camuflagem, mais que de fantasia e embelezamento" (SILVA, 2004, p. 178).

Paula (2004, p.80) defende que, embora não seja possível propor modelos genéricos de desenvolvimento aplicáveis a distintos territórios, é "possível definir algumas variáveis de observação a partir das quais seria possível estabelecer um diagnóstico situacional, e uma agenda de ações, para o incremento do desenvolvimento local". Em suma, é possível determinar modelos de planejamento do turismo que reconheçam, acumulem e preservem o que um território possui: seu patrimônio cultural, suas técnicas produtivas e atividades econômicas e recursos ambientais.

É fundamental compreender que o turismo não se dá a partir de uma fórmula única, e que para que haja o desenvolvimento de fato, deve movimentar aspectos sociais, culturais, econômicos, a fim de não gerar apenas o crescimento econômico. "Representa uma oportunidade de aumento das receitas, não somente para o país, mas também para a população" (SILVA; COSTA; CARVALHO, 2013, p. 03)

A valorização dos atributos territoriais das diferentes regiões pode levar ao desenvolvimento, pois "é em torno dos territórios que poderão ser descobertas novas configurações entre campo e cidade, capazes de propiciar oportunidades de geração de renda até aqui adormecidas" (ABROMAVAY, 1998, p.18). É o caso do 
município de São José do Barreiro, foco deste artigo, e que potencialmente possui na atividade turística um potencial caminho para o desenvolvimento.

\section{Estrutura turística e a cadeia do turismo}

No sentido de desenvolvimento socioeconômico, entende-se o turismo como um propulsor econômico e estimulador do bem-estar social, por meio das viagens e das explorações de lugares, mas caso não seja planejado e articulado de maneira eficaz, pode causar problemas como infraestrutura defasada, ruídos urbanos, desmatamento, crescimento desordenado da população, falta de capacitação e conhecimento das agências locais, entre outros.

Formas para a organização e estímulo das atividades turísticas vêm se estabelecendo no decorrer dos anos e uma delas, segundo a Secretaria de Turismo do Estado de São Paulo (2016), foi a criação em 1989 do Departamento de Apoio ao Desenvolvimento das Estâncias - DADE, atualmente denominado Departamento de Apoio ao Desenvolvimento das Estâncias - Dadetur, que disponibiliza verbas aos municípios reconhecidos como estâncias balneárias, climáticas, hidrominerais e turísticas.

Os municípios que se interligam ao Dadetur, para tornarem-se estâncias, partem do pressuposto de que possuem algum atrativo local, e que podem proporcionar condições de lazer aos turistas. O município de São José do Barreiro é classificado com estância turística por possuir essas características estipuladas pela Secretaria de Turismo do Estado de São Paulo.

Como política pública recente de estruturação do turismo nacional, o Ministério do Turismo reestruturou o antigo Plano Nacional do Turismo - PNT, no qual "estima-se que para o ano de 2022 o turismo seja responsável por 3,63 milhões de empregos. Estão incluídas as atividades relacionadas à hotelaria, agências de viagens, companhias aéreas, outros tipos de transportes de passageiros, restaurante e lazer" (BRASIL, 2018).

As atividades que formam uma cadeia produtiva, a cadeia do turismo, são apresentadas na Figura 1. A cadeia produtiva do turismo é estabelecida por interações dos segmentos envoltórios, para que o turismo ocorra de maneira eficaz. Para o Sebrae (2008), a cadeia produtiva do turismo é a malha sequenciada de atividades e segmentos produtivos, esta malha converge para a produção de bens e serviços, e articula-os com os seus stakeholders ou trade turístico. 
Figura 1. Cadeia Produtiva do Turismo

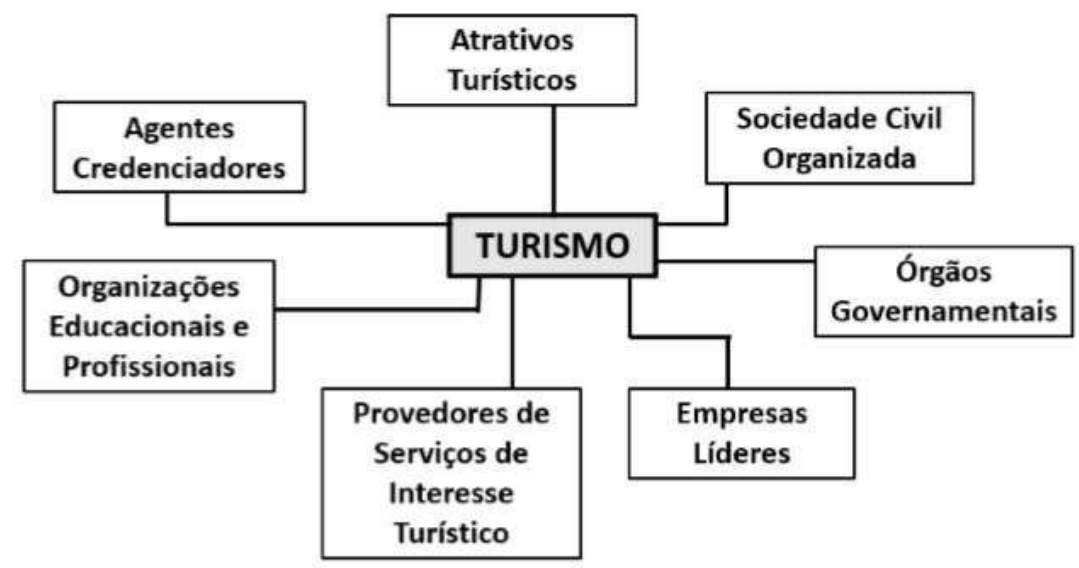

Fonte: Adaptada do portal institucional da Fecomércio - MG.

Para Lage e Milone (2001), o consumidor pode definir onde fazer o turismo, tendo em vista seus gostos e preferências específicas, notando as características de cada região, a estrutura para as necessidades e os atrativos que são ofertados e divulgados. Caso a cadeia produtiva esteja com problemas de planejamento, a experiência do turista no local visitado será impactada de alguma forma.

\section{Método}

A pesquisa caracteriza-se como descritiva, "que tem por finalidade investigar as características de determinada realidade ou mesmo descobrir variáveis componentes dessa realidade" (APPOLINÁRIO, 2006, p. 115). A abordagem é mista, quali-quantitativa, e triangulou dados resultantes das seguintes etapas: realização de entrevista semiestruturada com o prefeito (gestor público com mandato em 2013 a 2016) local, visto que o município não possuía na ocasião um Secretário de Turismo; aplicação de questionários estruturados fechados para uma amostra de 336 munícipes Barreirenses sobre a atividade turística, amostra calculada a partir da população total do município - 4.077 habitantes (IBGE, 2010) com 5\% de erro amostral e $95 \%$ de nível de confiança, com técnica de seleção de amostra foi não probabilística por acessibilidade, e observação sistemática nos atrativos turísticos no município.

O projeto foi submetido e aprovado por Comitê de Ética em Pesquisa, e a coleta de dados ocorreu no segundo semestre de 2016.

O locus de estudo é o município de São José do Barreiro, caracterizado por estância turística e que faz parte da Região Metropolitana do Vale do Paraíba, microrregião de Bananal - São Paulo, com população de 4.077 habitantes, segundo o Censo 2010 realizado pelo IBGE (2010).

Atualmente, São José do Barreiro tem como base de sua economia a agricultura (cana, abóbora, mandioca, milho, feijão e arroz), a pecuária leiteira e o turismo. Há no município oportunidade de desenvolvimento do turismo cultural, pela presença de fazendas e casarões de café, e por seus atrativos naturais, proporcionando o turismo de aventura, turismo rural e ecoturismo. Por causa dos seus atrativos, em 1998 o município foi elevado a Estância Turística de São José do Barreiro (IBGE, 2010). 
O município faz parte da região Metropolitana, que possui 39 municípios com características heterogêneas e 2,3 milhões de habitantes (EMPLASA, 2018), conforme Figura 2.

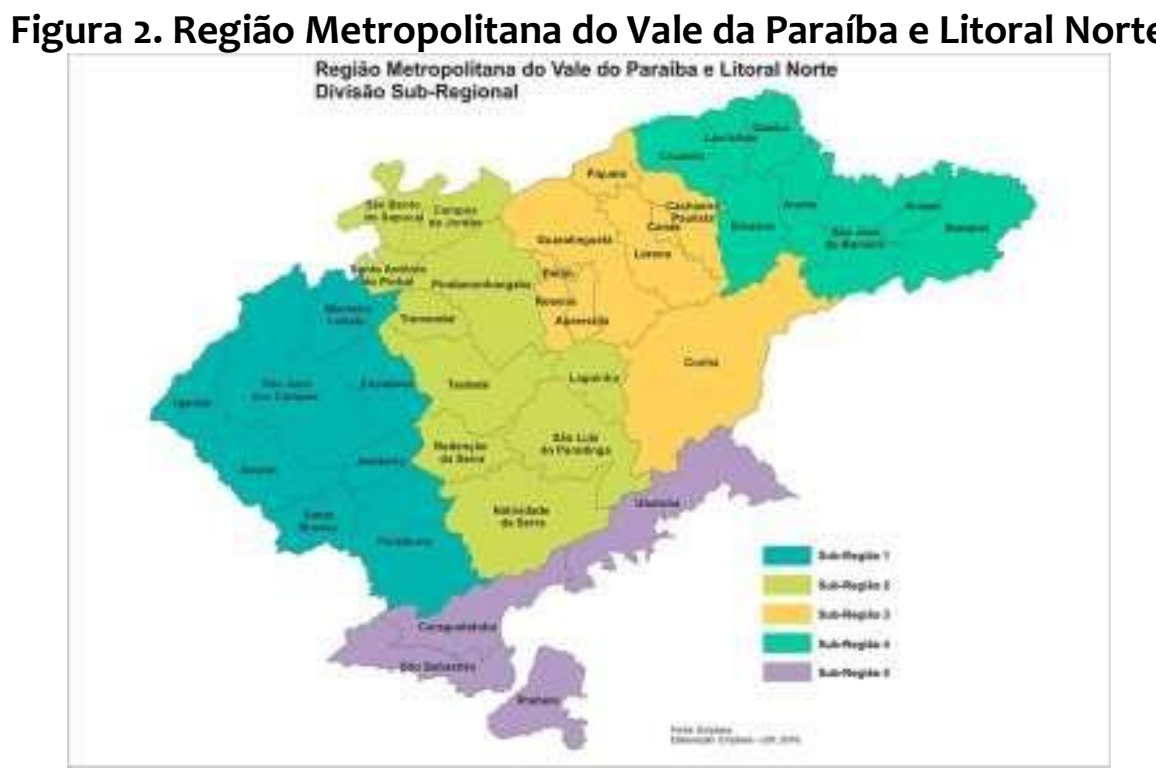

Fonte: Emplasa (2018).

São José do Barreiro apresentou, em 2013, baixo desempenho na dimensão economia do Índice Firjan de Desenvolvimento Municipal, a despeito do bom desempenho das outras dimensões, conforme Figura 3.

Figura 3. Índice Firjan de Desenvolvimento Municipal - São José do Barreiro

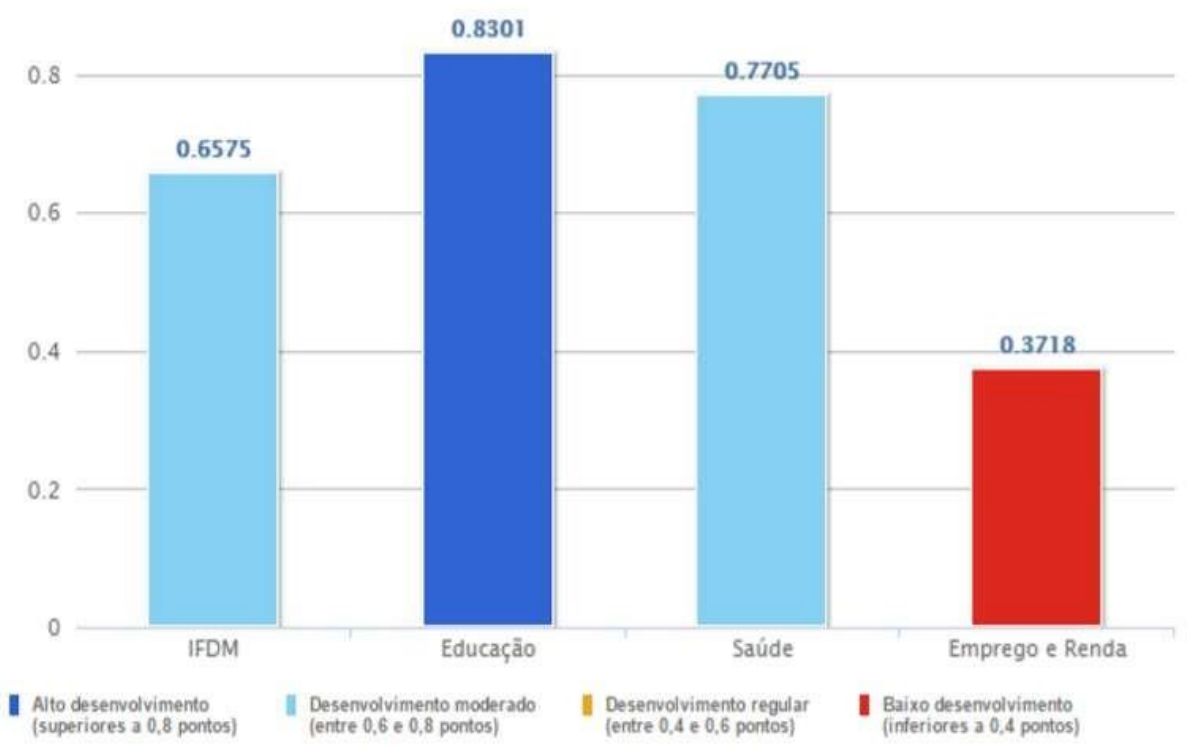

Fonte: Firjan (2013). 
Tal cenário demanda a busca de caminhos para ampliar emprego e renda, e o turismo, dadas as outras características locais e o reconhecimento do município como estância turística, apresenta-se como uma possibilidade para conciliar crescimento econômico a partir do potencial endógeno da localidade.

\section{Resultados e discussão}

A fim de colher as percepções do gestor local do município, a fase qualitativa da pesquisa permeou pelos seguintes temas, abordados por meio de aplicação de entrevista: caracterização do entrevistado: trajetória profissional, qualificação e envolvimento com o turismo; município como estância turística; turismo e desenvolvimento; atrativos turísticos; regionalização do turismo; e ações de comunicação e divulgação.

O entrevistado relatou que buscou se capacitar na área de turismo e que faz parte do trade de turismo, pois possui uma agência local: "E aí continuei na área de educação física até 98 , aí em 98 eu sai da parte de educação física e foquei na, só mesmo no turismo". Inclusive, percebe-se que houve persistência por parte dele, para que o município se tornasse Estância Turística: "daí fui procurar saber, o que é isso, Estância Turística, daí fiquei sabendo que era um recurso que o governo do estado dava para algumas cidades que tinha potencial turístico pra montar estrutura turística do município, daí fiquei super entusiasmado com isso, e falei ah [sic], vou trabalhar para São José do Barreiro [...]."

Já sobre a empregabilidade na área para o município, "e referente ao emprego e renda se você for ver, é o momento da crise, o que está acontecendo, São José do Barreiro está indo bem nisso e o que aconteceu no final do ano passado [2015]? As famílias que haviam se mudado de São José do Barreiro começaram a voltar".

Foi perguntado ao gestor se os recursos gerados pelo turismo são significativos para a arrecadação do município, e o mesmo informou que: "Lógico! Sim, principalmente na geração de empregos. Se tudo continuar do jeito que está, daqui dois anos, São José do Barreiro será um dos grandes estímulos desta região do Vale do Paraíba". E foi questionado se havia alguma articulação com os demais municípios da região para atrair turistas. O entrevistado informou que: "o objetivo é esse, e agora com a melhoria das estradas, as pessoas acabam fazendo isso naturalmente", não mencionado nenhum plano estruturado de regionalização do turismo entre os municípios.

Também destaco que o destino da utilização da verba disponibilizada pelo Dadetur estava direcionado para "calçamento de pontos críticos das estradas turísticas, a revitalização do portal, o centro de informações turísticas e secretaria de turismo e a construção de mirantes na estrada do parque nacional", buscando desenvolver a infraestrutura do município ao invés de direcionamentos específicos para a divulgação do município na mídia.

Sobre o plano de mídia, para divulgação de São José do Barreiro, o entrevistado afirmou que já realizaram anúncios em TV, e em outros veículos de comunicação, mas o foco principal e o plano de mídia estão no meio digital, com ações no Facebook. "Na rede social, basicamente fechamos no Facebook, a gente faz uma divulgação no Facebook e aí o que as pessoas fazem, eles curtem e 
compartilham".

Verificou-se que as ações realizadas são táticas e pontuais, sem um conceito estratégico de sustentação para nortear o turismo de forma articulada com um planejamento territorial.

A segunda etapa da pesquisa, de abordagem quantitativa, consistiu em uma pesquisa de campo com barreirenses com faixa etária acima de 20 anos. A amostra foi caracterizada por moradores do centro com $36 \%$ dos entrevistados, seguido por $19 \%$ na Cidade Vila Nova; $18 \%$ em São Sebastião e 13\% em Formoso. Referente ao sexo de registro, $54 \%$ dos respondentes são do sexo feminino, e $46 \%$ são do masculino. 0 Gráfico 1 apresenta a divisão etária da amostra.

\section{Gráfico 1. Faixa etária}

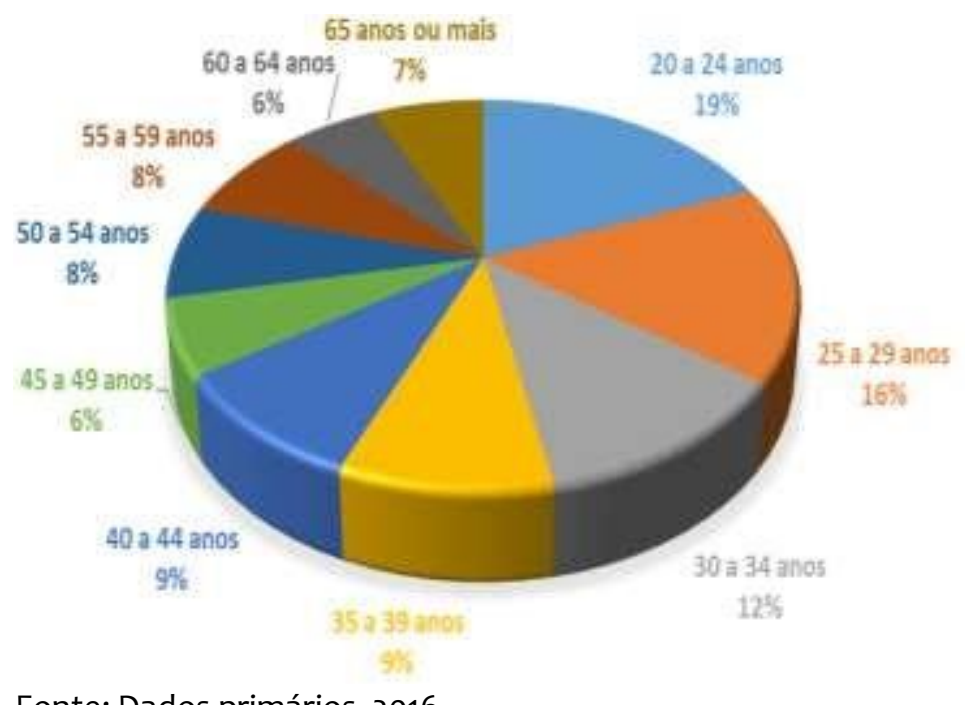

Fonte: Dados primários, 2016.

A renda familiar mensal da amostra apontou que a maioria, $41 \%$, possui renda de até $\mathrm{R} \$ 1.760,00$ (equivalente a dois salários mínimos), seguindo por 32\%, com renda de $R \$ 1.761,00$ a $R \$ 3.520,00$, e $4 \%$ da amostra possui renda acima de $\mathrm{R}$ 5.280,00 (mais de seis salários mínimos), o que demonstra uma predominância de população de baixa renda, condizente com os dados econômicos apontados pelo Índice de Desenvolvimento Municipal FIRJAN (ver Figura 3).

Nota-se que referente ao nível de escolaridade dos entrevistados, 0,3\% equivale a não alfabetizados, $5 \%$ possuem ensino fundamental completo; $45 \%$ possuem ensino médio completo; $10 \%$ superior completo; $4 \%$ são especialistas/pósgraduado e $0,6 \%$ registrou possuir mestrado.

Sobre a localidade de trabalho, $56 \%$ dos entrevistados trabalham em São José do Barreiro e 44\% exercem atividades nos municípios de Resende, Cruzeiro, Areias, Arapeí, Bananal, Guaratinguetá e Rio de Janeiro, o que denota a falta de oportunidades de trabalho no município.

A área de Comércio e Serviços se destaca com 55\% do trabalho dos entrevistados, seguido por $21 \%$ de donas de casa, e $12 \%$ aposentados. Apenas $2 \%$ dos entrevistados exercem atividade remunerada diretamente com o turismo, o que é pouco representativo para um município com o status de estância turística.

O Gráfico 2 apresenta que apenas 96 dos entrevistados, o que corresponde a 
$29 \%$ da amostra, declararam possuir interesse em trabalhar com o turismo, e 201 pessoas (60\%) afirmaram que não gostariam de trabalhar nesta área.

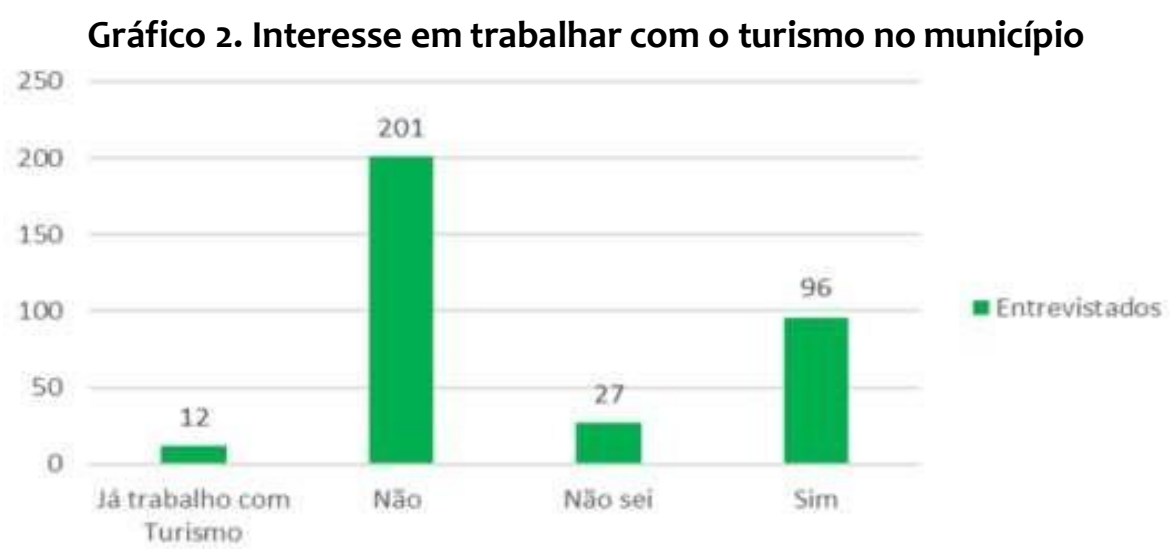

Fonte: Dados primários, 2016.

Uma hipótese para explicar tal resultado pode estar no fato de as dimensões Educação e Saúde se apresentarem com bom desempenho na composição do Índice de Desenvolvimento Municipal FIRJAN (ver Figura 1). Portanto, mesmo com baixa renda, em um município de pequeno porte é possível manter uma qualidade satisfatória. Ressalta-se que os baixos indicadores nem sempre se refletem diretamente na percepção negativa dos munícipes, no entanto, os indicadores devem ser considerados como um dos parâmetros para a avaliação da condição do território, e para a fundamentação do planejamento territorial.

Quanto ao conhecimento sobre o status e estância turística do município, o resultado é apresentado no Gráfico 03.

\section{Gráfico 3. Identificação de São José do Barreiro como Estância Turística}

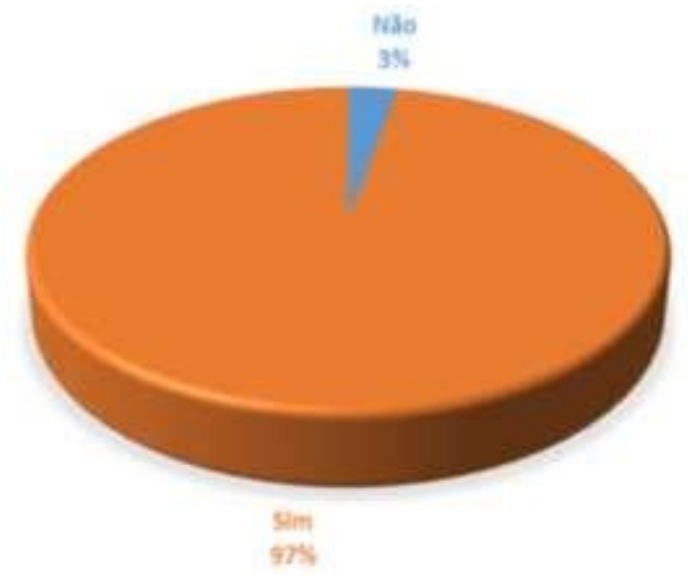

Fonte: Dados primários, 2016. 
Perguntou-se aos munícipes se o turismo traz oportunidades empreendedoras ao município. 64\% acreditam que sim, conforme Gráfico 4.

\section{Gráfico 4. 0 turismo como oportunidades empreendedoras}

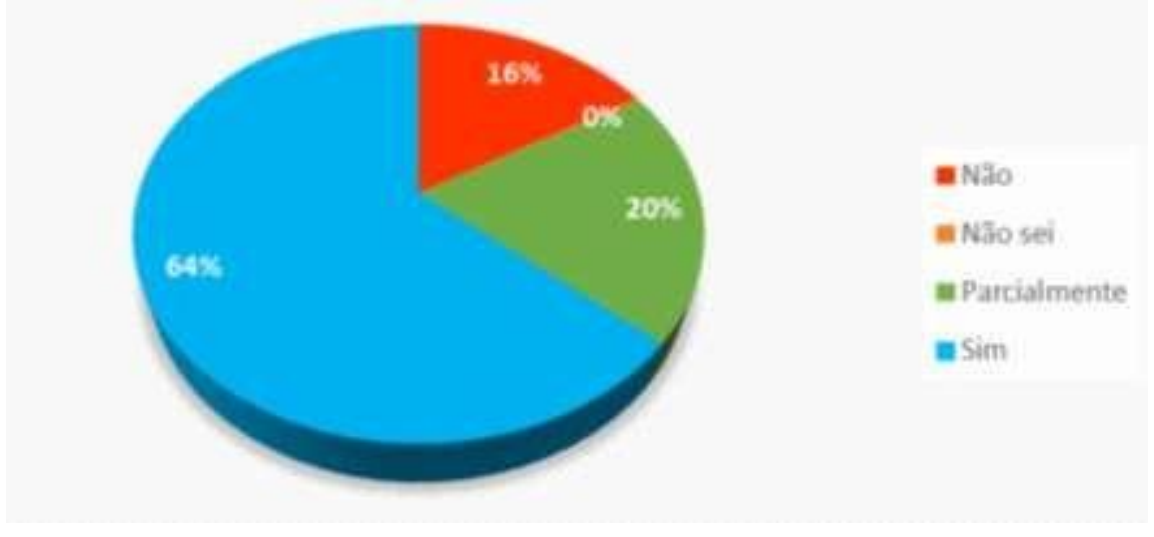

Fonte: Dados primários, 2016.

Se a maioria da amostra populacional acredita que o turismo traz empregos, gera renda e oportunidades empreendedoras, pode-se refletir as razões pelas quais muitos não gostariam de trabalhar nessa área. Ao buscar o entendimento dessas questões, perguntou-se aos munícipes se a prefeitura investe em turismo como opção de atividade econômica no município, e 55\% informaram que não há o investimento, 20\% parcialmente, 9\% não souberam responder e apenas $16 \%$ afirmaram que há investimentos (Gráfico 5), percepção conflitante com a fala do gestor referente à representatividade e investimento na geração de empregos e capacitação de profissionais para o setor turístico.

\section{Gráfico 5. Investimento da prefeitura no turismo como atividade econômica}

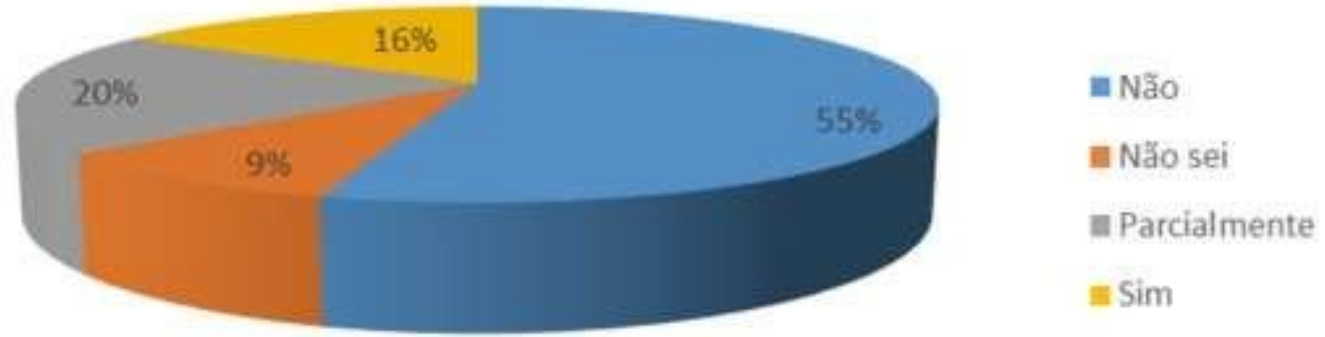

Fonte: Dados primários, 2016.

Mesmo demostrando problemas, foi perguntado se o turismo pode gerar emprego e renda ao município e $81 \%$ da amostra respondeu que sim, mesmo não havendo interesse dos munícipes em trabalhar nessa atividade. $O$ desinteresse em atuar no setor turístico pode ser reflexo da ausência de ações de formação, capacitação de mão de obra para o setor, conforme Gráfico 6. 


\section{Gráfico 6. Cursos de qualificação ofertados pela prefeitura}

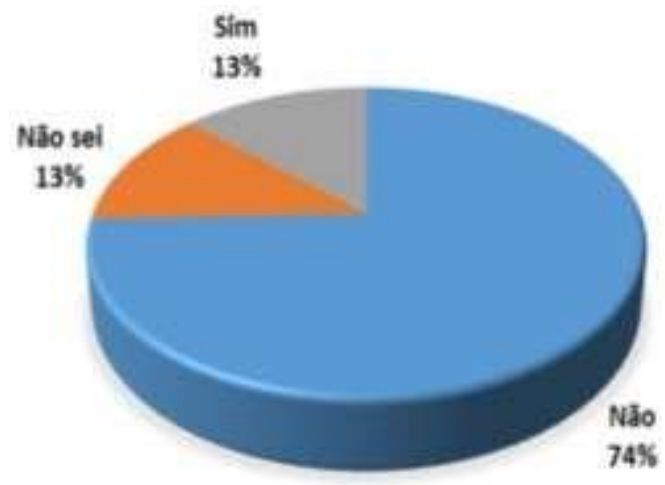

Fonte: Dados primários, 2016.

Para que haja o desenvolvimento do turismo no município, a população também precisa querer e sentir-se à vontade para receber os turistas. Dessa forma, perguntou-se à amostra se ela se sentia valorizada com a visita de turistas no município. E 58\% informou sim, segundo o Gráfico 7.

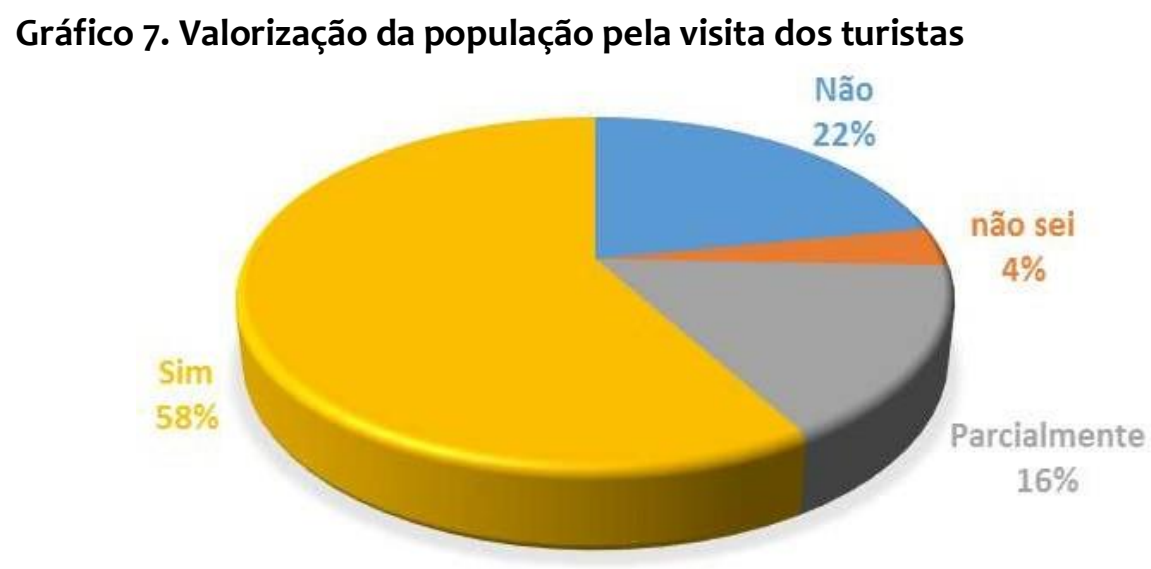

Fonte: Dados primários, 2016.

De forma geral, os turistas são cordiais e curiosos na expectativa de explorar o município, conforme resultados do Gráfico 8. 
Turismo como vetor de desenvolvimento local: análise da estrutura turística no Município de São José do Barreiro - SP

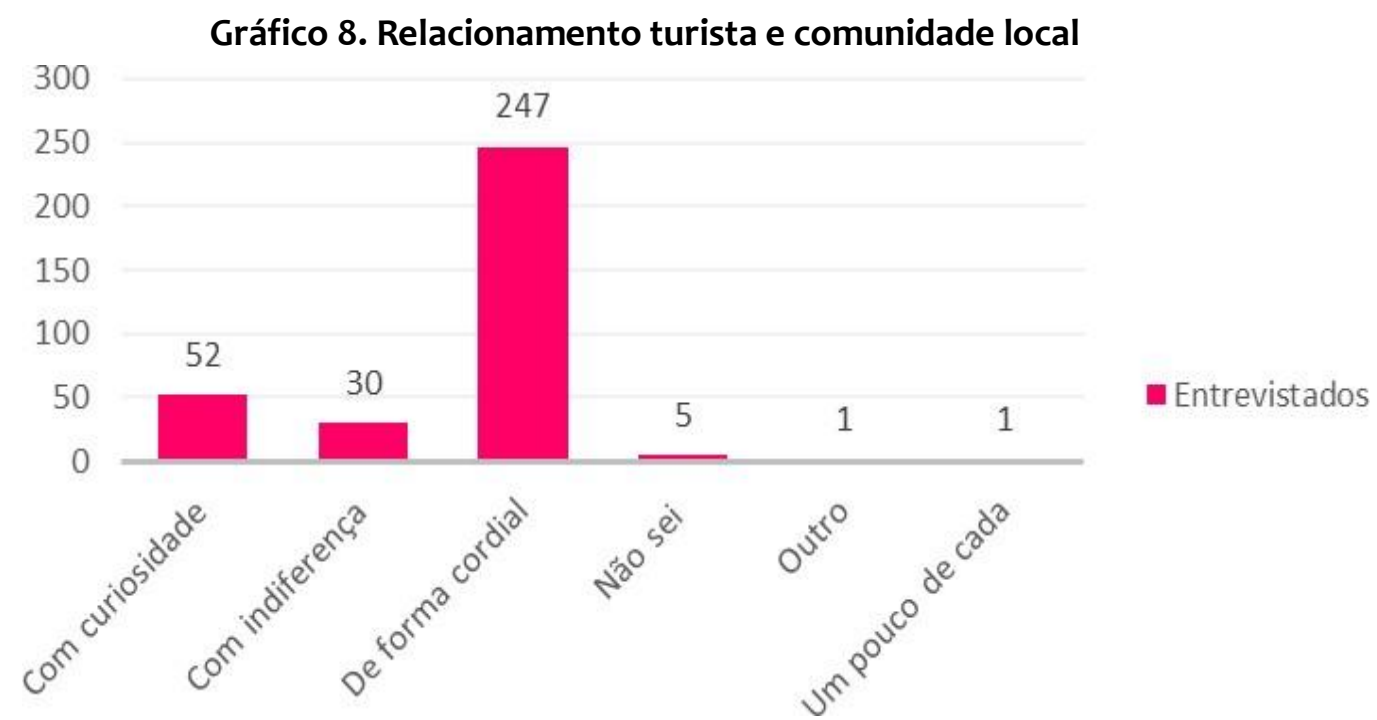

Fonte: Dados primários, 2016.

A população pesquisada acredita que os turistas visitam o município para conviver com a natureza, pelo relaxamento, lazer, entretenimento, esporte de aventura e artesanato.

Por fim, foram entrevistados munícipes que frequentavam os atrativos do município, com o intuito de verificar se esses atrativos estavam integrados à dinâmica social da cidade, diferentemente de atrativos direcionados apenas aos turistas, tais como turismo de resort, que geralmente excluem os locais e se constituem como um modelo de turismo predatório.

Tabela 1. Lista dos atrativos utilizados pela amostra barreirense

\begin{tabular}{|c|c|c|}
\multicolumn{1}{c|}{} & \multicolumn{2}{c|}{$\begin{array}{c}\text { Respos } \\
\text { tas }\end{array}$} \\
\cline { 2 - 3 } \multicolumn{1}{c|}{ Atrativo } & Quantidade & $\begin{array}{c}\text { \% comparada a amostra } \\
\text { aplicada }\end{array}$ \\
\hline Balneário Água Santa & 274 & $82 \%$ \\
\hline Carnaval & 265 & $79 \%$ \\
\hline Festa de São José & 264 & $79 \%$ \\
\hline Cachoeirão & 244 & $73 \%$ \\
\hline Parque N. Serra da Bocaína & 234 & $70 \%$ \\
\hline Igreja de São José & 218 & $65 \%$ \\
\hline Cachoeira Santo Izidro & 192 & $57 \%$ \\
\hline Feirinha em Formoso & 190 & $57 \%$ \\
\hline Trilha do Ouro & 159 & $47 \%$ \\
\hline Cachoeira da Usina & 156 & $46 \%$ \\
\hline Represa do Funil & 146 & $43 \%$ \\
\hline Rampa de Voo Livre & 134 & $40 \%$ \\
\hline Cachoeira da Mata & 128 & $38 \%$ \\
\hline Fazenda Pau d'alho & 115 & $34 \%$ \\
\hline Camping & 94 & $28 \%$ \\
\hline
\end{tabular}


(conclusão)

\begin{tabular}{|c|c|c|}
\cline { 2 - 3 } \multicolumn{1}{c|}{} & \multicolumn{2}{c|}{$\begin{array}{c}\text { Respos } \\
\text { tas }\end{array}$} \\
\hline Atrativo & Quantidade & $\begin{array}{c}\text { \% comparada a amostra } \\
\text { aplicada }\end{array}$ \\
\hline Cemitério dos Escravos & 88 & $26 \%$ \\
\hline Fazenda São Francisco & 84 & $25 \%$ \\
\hline Cachoeira da Esmeralda & 79 & $24 \%$ \\
\hline Casa de Pedras Ruínas & 78 & $23 \%$ \\
\hline Pedra Redonda & 78 & $23 \%$ \\
\hline Cachoeira do Paredão & 76 & $23 \%$ \\
\hline Cachoeira das Posses & 55 & $16 \%$ \\
\hline Pico da Bacia & 55 & $16 \%$ \\
\hline Lagoa da Siriema & 52 & $15 \%$ \\
\hline Trilha da Bocaininha & 53 & $16 \%$ \\
\hline Pedra da Graúna & 47 & $14 \%$ \\
\hline Refugio Vale dos Veados & 45 & $13 \%$ \\
\hline Fazenda Lagoa da Saudade & 32 & $10 \%$ \\
\hline Rota Franciscana & 28 & $8 \%$ \\
\hline Fazenda Santa Tereza Rural & 24 & $7 \%$ \\
\hline
\end{tabular}

Fonte: Dados primários, 2016.

Como terceira fonte de coleta de dados, foi realizada a observação de amostra dos atrativos do município, com registro em formulário específicos, para verificação da estrutura existente em cada um dos atrativos.

O município possui 48 atrativos naturais, artificiais, históricos, e voltados ao lazer e entretenimento possibilitando a realização de turismo cultural, turismo de aventura, ecoturismo e turismo rural. Estes são divulgados em mapa turístico e no site oficial da prefeitura. Nota-se que muitos dos locais selecionados no mapa fazem parte do trade turístico municipal, o que denota que o mapa é usado como forma de divulgação de alguns estabelecimentos. Outro item de destaque no Mapa Turístico é que não há coordenadas para que o turista chegue ao local desejado, dificultando o acesso a informação.

Dentre os atrativos, uma amostra de 13 locais foi visitada e observada a respeito da estrutura e serviços oferecidos aos turistas. Os locais com estrutura de fácil acesso ao turista são o Balneário Água Santa, Cachoeirão e a Igreja de São José. Nos demais locais há dificuldade de acesso, caso das cachoeiras e dos patrimônios históricos Fazenda Pau'alho e Cemitério Velho. Este último fica fechado e para acesso é necessário agendamento prévio.

Há pouca sinalização dos atrativos no município e muitas placas degradadas pelo tempo. Falta estrutura turística e receptiva nos espaços, inclusive nas proximidades as cachoeiras, que são visitadas pela maioria dos turistas e população local. 


\section{Considerações finais}

O objetivo deste artigo foi verificar como o município São José do Barreiro SP organiza e estrutura sua atividade turística com vistas ao desenvolvimento local.

Por meio de uma análise dos atrativos turísticos triangulada, pôde-se chegar ao objetivo de pesquisa e observar que o município possui atrativos importantes e que contribuem economicamente para geração de renda local, mas falta, para a atividade turística, a estruturação municipal, políticas públicas locais efetivas e mão de obra qualificada para atuação específica na área.

Foi verificado o fato de o município receber verba específica do Dadetur Departamento de Apoio ao Desenvolvimento das Estâncias para investimentos locais. Como ameaça ao município há a falta de estrutura e acesso aos principais atrativos, a falta de planejamento estratégico, a descontinuidade política, o que dificulta ações de forma integrada e efetivas a longo prazo.

O turismo de São José do Barreiro, tal qual é estruturado atualmente, não impacta de forma negativa no município, visto que os atrativos estão integrados à dinâmica local e são usufruídos também pelos moradores. No entanto, a estrutura oferecida não é suficiente para ofertar ao turista condições mínimas de acesso e informação. Isso não impede que haja visitação aos atrativos, mas pode deixar de atrair uma quantidade maior de turistas que preferem visitar locais mais estruturados. É fato que o município possui condições de ampliar a geração de emprego e renda com o setor turístico a partir dos atrativos existentes, aproveitando seu potencial endógeno.

Há fatores de vulnerabilidade e limitações ao município, mas que podem ser minimizados com ações integradas entre poder público, setor privado e comunidade local.

\section{REFERÊNCIAS}

ABRAMOVAY, Ricardo. Agricultura familiar e desenvolvimento territorial. Reforma agrária. Revista da Associação Brasileira de Reforma Agrária. v. 28. n.1. São Paulo: 1998.

ATELJEVIC, Jovo; PAGE, Stephen J.; ALMEIDA, Marcelo Vilela de. Turismo e Empreendedorismo. Rio de Janeiro: Elsevier, 2011. 232 p.

DALLABRIDA, Valdir Roque. Governança territorial e desenvolvimento: as experiências de descentralização político-administrativa no Brasil como exemplos de institucionalização de novas escalas territoriais de governança. I Circuito de debates Acadêmicos IPEA. Anais.

2011. Disponível em:

<. http://www.ipea.gov.br/code2011/chamada2011/pdf/area7/area7-artig011.pdf >

Acesso em: 30 maio 2018.

EMPLASA. Região Metropolitana do Vale do Paraíba e Litoral Norte. 2018. 
Disponível em: < https://www.emplasa.sp.gov.br/RMVPLN> Acesso em: 13 set. 2017.

FIRJAN. IFDM - Índice Firjan de Desenvolvimento Municipal. 2013. Disponível em: <http://www.firjan.com.br/ifdm/>. Acesso em: 20 abr. 2016.

BARATA, Clara. Para quem vive em Barcelona, o turismo é o principal problema. Público. 5 de Agosto de 2017. Disponível em:

< https://www.publico.pt/2017/08/05/mundo/noticia/para-quem-vive-embarcelona-o-turismo- e-o-principal-problema-1781407> Acesso em: 01 jun. 2018.

BRASIL. MINISTÉRIO DO TURISMO. Programa de Regionalização do Turismo: Diretrizes. Brasília, 2013. 47 p. Disponível em: <http://www.turismo.gov.br/images/programas_acoes_home/PROGRAMA_DE_ REGI ONALIZACAO_DO_TURISMO_-_DIRETRIZZES.pdf $>$. Acesso em: 08 out. 2015.

FECOMERCIO MG, Federação do Comércio - Cadeia Produtiva do Turismo. Disponível em: <http://www.fecomerciomg.org.br/produtoseservicos/turismo/cadeia-produtiva-do- turismo/>. Acesso em: 28 jul. 2016.

FLORES, M. A identidade cultural do território como base de estratégias de desenvolvimento-uma visão do estado da arte. Territorios com identidad cultural. Rimisp $20^{\circ}$. Aniversário, 2006.

FURTADO, Celso. A dialética do desenvolvimento. Rio de Janeiro: Fundo de Cultura, 1964.

G1. Moradores de Veneza fazem protesto contra turismo de massa Milhares de venezianos marcharam contra a degradação provocada pelo excesso de turistas, que estaria deixando insustentável a vida na cidade italiana.G1. 03 jul. 2017. Disponível em: < https://g1.globo.com/turismo-eviagem/noticia/moradores-de-veneza- realizam-protesto-contra-turismo-demassa.ghtml> Acesso em: 01 jun. 2018.

GOGONEA, Rodica-Manuela et al. Tourism Pressure at the Regional Level in the Context of Sustainable Development in Romania. Sustainability. v. 9, n. 698, 2017. Disponível em: < www.mdpi.com/journal/sustainability> doi:10.3390/su9050698 Acesso em: 01 jun. 2018.

GUTLICH, George Rembrandt. A expressão cultural como alternativa econômica para o município de São José do Barreiro: um estudo de possibilidades. Revista Brasileira de Gestão e Desenvolvimento Regional. Taubaté, v. 12, n. 1, p.393-409, jan. 2016. Trimestral. Disponível em: <http://www.rbgdr.net/revista/index.php/rbgdr/article/view/2136>. Acesso em: 12 jul. 2016.

IBGE - Instituto Brasileiro de Geografia e Estatística (Ed.). IBGE cidades. São 
José do Barreiro. 2010. Disponível em:

<http://cidades.ibge.gov.br/xtras/temas.php?lang=\&codmun=354960\&idtem $\mathrm{a}=16 \&$ sear ch=sao-paulo|sao-jose-do-barreiro|sintese-das-informacoes $>$.

Acesso em: 22 abr. 2016.

KÖRÖSSY, Nathália. Do "turismo predatório" ao "turismo sustentável”: uma revisão sobre a origem e a consolidação do discurso da sustentabilidade na atividade turística. Caderno Virtual de Turismo v. 8, n 2, 2008, pp. 56-68. Disponível em: <http://www.ivt.coppe.ufrj.br/caderno/index.php/caderno/article/viewFile/238/178 $>$ Acesso em: 27 maio 2018.

LAGE, Beatriz Helena Gelas; MILONE, Paulo Cesar. Economia do turismo. 7. ed. São Paulo: Atlas, 2001.

LIU, Canmian et al. Measurement and prediction of regional tourism sustainability: an analysis of the Yangtze River Economic Zone, China. Sustainability v. 10, n. 1321, 2018. Disponível em: <www.mdpi.com/journal/sustainability> doi:10.3390/su10051321Acesso em: 01 jun. 2018.

LOBATO, Monteiro. Cidades Mortas. Revista do Brasil, 1919.

Ministério do Turismo (Org.). Plano Nacional de Turismo: o turismo fazendo muito mais pelo brasil. 2013. Disponível em: <http://www.turismo.gov.br/201503-09-13-5427.html>. Acesso em: 19 jul. 2015.

MOTA, Keila Cristina Nicolau. Marketing Turístico: promovendo uma atividade sazonal. São Paulo: Atlas, 2001, 219 p.

NAIGEBORIN, Mariana Barrichello. O Movimento devagar e seu significado plural na contemporaneidade mutante. Dissertação (Mestrado em Ciências da Comunicação). ECA, Universidade de São Paulo, São Paulo, 2011.

OLIVEIRA, Antônio Pereira. Turismo e Desenvolvimento: Planejamento e Organização. 5. ed. São Paulo: Atlas, 2005.

PAULO, Juarez de. Territórios, redes e desenvolvimento. In: LAGES, V.; BRAGA, C.; MORELLI, G. (Org.). Territórios em movimento: cultura e identidade como estratégia de inserção competitiva. Rio de Janeiro: Relume Dumará; Brasília: SEBRAE, 2004. Disponível em: <http://inspirebr.com.br/uploads/midiateca/d64C55dfd943251ede2b6330035a5994 .pdf\#page=2 4> Acesso em: 03 jun.2018.

SACHS, Ignacy. Desenvolvimento, um conceito transdisciplinar por excelência. Revista Tempo Brasileiro. Rio de Janeiro, 2003.

SÃO PAULO, Portal da Secretaria do Estado. Estâncias. Disponível em: 
<http://www.saopaulo.sp.gov.br/conhecasp/estancias>. Acesso em: 13 jul. 2016.

SANTOS, Moacir José dos; HANAOKA, Fernando; CARNIELLO, Monica Franchi. Turismo e desenvolvimento na microrregião de Bananal - SP. VII Seminário Internacional sobre Desenvolvimento Regional. 2015. Disponível em: < https://online.unisc.br/acadnet/anais/index.php/sidr/article/viewFile/13386/2551> Acesso em 07 nov. 2017.

SEN, Amartya. Desenvolvimento como liberdade, S. Paulo: Cia. das Letras, 2000.

SILVA, Fabiana dos Santos; COSTA, Sarany Rodrigues da; CARVALHO, Conceição de Maria Belfort de. Políticas públicas de turismo no Brasil: estratégias para administração da atividade no país. In: Simpósio de Excelência em Gestão e Tecnologia, 10, 2013, Resende. Simpósio. Resende: Aedb, 2013. v. 1, p. 1 - 10. Disponível em:

<http://www.aedb.br/seget/arquivos/artigos13/36218351.pdf>. Acesso em: 27 jul. 2016.

SILVA, Maria da Gloria Lanci da. Cidades Turísticas: Identidades e Cenários de Lazer. 1 ed. São Paulo: Aleph, 2004. 191 p.

VIEIRA, Edson Trajano; SANTOS, Moacir José dos. Industrialização e desenvolvimento regional: política do CODIVAP no Vale do Paraíba na década de 1970 . Desenvolvimento Regional em Debate, n. 2, p. 161-181, 2012.

WEIDENFELD, Adi. Tourism Diversification and Its Implications for Smart Specialisation. Sustainability. v. 10, n. 319, 2018. Disponível em: < www.mdpi.com/journal/sustainability> . Acesso em: 01 jun. 2018. DOI:10.3390/su10020319

WORLD TOURISM ORGANIZATION (WTO). Guide for Local Authorities on Developing Sustainable Tourism. World Tourism Organization: Madrid, Spain, 1998.

Monica Franchi Carniello. Doutora em Comunicação e Semiótica (PUC SP). Possui pós-doutorado pela Universidade Metodista de São Paulos e pela Universidade do Minho - Portugal. Docente do Mestrado em Planejamento e Desenvolvimento Regional da Universidade de Taubaté. monicafcarniello@gmail.com

Cláudia Liciely Barbosa e Silva. Mestre em Planejamento e Desenvolvimento Regional - Universidade de Taubaté. Docente da Uniesp, Guaratinguetá. claudialiciely@yahoo.com.br 